Mohamed et al., Afr J Tradit Complement Altern Med. (2012) 9(3):329-335

Publisher: African Networks on Ethnomedicines

Web page: /http://journals.sfu.ca/africanem/index.php/ajtcam/index

http://dx.doi.org/10.4314/ajtcam.v9i3.5

\title{
HISTOLOGICAL CHANGES IN MALE ACCESSORY REPRODUCTIVE ORGANS IN RATS EXPOSED TO CIGARETTE SMOKE AND THE PROTECTIVE EFFECT OF HONEY SUPPLEMENTATION
}

\author{
Mahaneem Mohamed $^{* 1}$, Siti Amrah Sulaiman ${ }^{2}$, Hasnan Jaafar ${ }^{3}$ \\ ${ }^{1}$ Department of Physiology, ${ }^{2}$ Department of Pharmacology, ${ }^{3}$ Department of Pathology, School of Medical \\ Sciences, Universiti Sains Malaysia, 16150 Kubang Kerian, Kelantan, Malaysia. \\ *E-mail: mahaneem@kck.usm.my
}

\begin{abstract}
The effect of cigarette smoke (CS) on histology of male accessory reproductive organs and the possible protective effect of honey supplementation in rats were investigated in this study. Rats received distilled water, honey, CS exposure or honey plus CS exposure. Honey (1.2 g/kg body weight/day) was administered by gavage and CS exposure (3 times per day) was done in a chamber for 13 weeks. CS exposure significantly increased relative weight of epididymis and ventral prostate. There were also significantly increased number of clear cells and epithelial height of cauda epididymis as well as severe interstitial oedema and decreased epithelial height of prostate gland. However, with the supplementation of honey, these histological changes were significantly reversed suggesting the protective effect of honey against the toxic effect of CS on male accessory reproductive organs in rats.
\end{abstract}

Key words: honey, cigarette smoke, accessory reproductive organ, histology, male rat

\section{Introduction}

Experimental studies have been shown that cigarette smoke (CS) exposure produces testicular damage. Degenerated and lower number of Leydig cells (Yardimci et al., 1997) as well as significant decrease in germ cell count and seminiferous tubule diameter in testis is found when rats are exposed to CS for 45 and 60 days (Rajpurkar et al., 2000a, Ahmadnia et al., 2007). However, little is known on the effect of CS on male accessory reproductive organs such as prostate, epididymis, seminal vesicle and coagulating gland. Rats treated intraperitoneally with nicotine, one of the main compounds present in CS, for 30 days have lower relative weight and decreased epithelial height of epididymis and vas deferens as compared to controls. There are also some alterations in their biochemical contents such as lower levels of protein, nucleic acids, cholesterol and acid phosphatase activity as well as higher level of alkaline phosphatase activity. These changes may cause unfavourable environment in epididymis and vas deferens for sperm maturation and motility (Londonkar et al., 1997). In another study, nicotine treatment for 90 days also causes atrophy of the epithelial cells with reduction in their expression of acid phosphatase in supranuclear and apical regions of ventral prostate in rats (Carvalho et al., 2006). It has been suggested that CS, which contains free radicals, causes oxidative damage as significantly increased lipid peroxidation as well as decreased glutathione level and glutathione peroxidase activity are found in rat testis after 45 days exposure to CS (Rajpurkar et al., 2000b).

Honey is a natural product of honey bees formed from nectar collected from blossoms and has antioxidant properties (Beretta et al., 2005, Perez et al., 2006, Mohamed et al., 2010). Phenolic compounds have been suggested to be the main antioxidant compounds in the honey as highly significant correlations are found between total phenolic contents and antioxidant and antiradical activities of honey (Beretta et al., 2005). To date, whether honey supplementation has any protective effect against the toxic effects of CS on male accessory reproductive organs has yet to be reported. Therefore, this study was undertaken to investigate the effect of CS on histology of male accessory reproductive organs and the possible protective effect of honey supplementation in rats.

\section{Materials and Methods \\ Honey sample and chemicals}

A wild multifloral honey used in this study was supplied by Federal Agricultural Marketing Authority (FAMA), Malaysia. It was collected from Apis dorsata's beehive built on a tall tree, Koompassia excelsa which is locally named 'Tualang' tree that grows in the Rain Forest of Kedah, Malaysia. It was collected in March 2007, filtered to remove solid particles and concentrated ( $20 \% \mathrm{w} / \mathrm{v}$ water) by oven drying at $40^{\circ} \mathrm{C}$ by the supplier. All the chemicals and reagents used were of analytical grade. 
Publisher: African Networks on Ethnomedicines

Web page: /http://journals.sfu.ca/africanem/index.php/ajtcam/index

http://dx.doi.org/10.4314/ajtcam.v9i3.5

Animals

Thirty-two adult male Sprague-Dawley rats, aged 10 weeks (270-320 g) were obtained from the Laboratory Animal Research Unit, Health Campus, Universiti Sains Malaysia and individually placed in a polycarbonate cage. They were maintained on a 12-hr light/dark cycle at $22 \pm 2{ }^{\circ} \mathrm{C}$, provided a standard pellet diet and water ad libitum, and acclimatised to the environment for 2 weeks prior to the experiment. This study protocol was approved by the Animal Ethics Committee, Universiti Sains Malaysia (PPSG/07(A)/044/2007[32]) and the animals were handled in accordance with the Guide for the Care and Use of Laboratory Animals by National Institute of Health.

\section{Experimental design}

Rats were randomly divided into 4 groups (n=8/group) i.e. control, honey (H), cigarette smoke (CS) and honey plus CS $(\mathrm{H}+\mathrm{CS})$. Rats in control and $\mathrm{CS}$ groups received distilled water $(0.5 \mathrm{~mL} /$ day $)$ while rats in $\mathrm{H}$ and $\mathrm{H}+\mathrm{CS}$ groups received freshly prepared honey (1.2 $\mathrm{g} / \mathrm{kg}$ body weight/day) by oral gavage. This dose was extrapolated relative to the local human consumption of honey $(0.2 \mathrm{~g} / \mathrm{kg} /$ day $)$. Rats in CS and H+CS groups were exposed to CS for 3 times daily using a whole body smoke exposure chamber (45 x 25 × $20 \mathrm{~cm}$ with 2 compartments). For each exposure, 10 cigarettes were burnt in a compartment and the smoke produced was continuously ventilated by 2 air pumps to another compartment where the rats were placed and exposed to CS for 8 min (Cesar-Neto et al., 2003). Rats in the control and $\mathrm{H}$ groups were subjected to the similar conditions but exposed to room air. After 13 weeks of treatment, rats were sacrificed by an overdose of diethyl ether anaesthesia. Male accessory reproductive organs such as epididymis, ventral prostate and seminal vesicles attached with coagulating glands were carefully dissected out, weighed and processed for histological study. The relative weights of these organs (in comparison to body weight in percentage) were also calculated.

\section{Histological study}

Epididymis was fixed in Bouin's solution for 24 hrs while ventral prostate, seminal vesicles and coagulating glands were fixed in $10 \%$ formalin for 2 weeks. Then cauda epididymis and other organs were cut vertically and transversely, respectively, dehydrated and embedded in paraffin blocks. Each tissue block was sectioned into $5 \mu \mathrm{m}$ thickness, stained with hematoxylin and eosin, and evaluated histologically using a light microscope and an image analyzer (Soft Imaging System, Olympus, UK). Each tissue section was assessed for histological changes such as epithelial atrophy, interstitial oedema and vacuoles of the epithelial cells. The mean epithelial heights of 20 random tubules of cauda epididymis and ventral prostate were measured at 40x magnification.

\section{Statistical Analyses}

Statistical analyses were carried out using the Statistical Package for Social Science (SPSS) version 12.0.1. Data with normal distribution and homogenous variance were analysed using One-way analysis of variance (ANOVA) followed by Tukey's HSD post-hoc test and presented as mean (standard deviation). Meanwhile, data with non-normal distribution and nonhomogenoues variance were analysed by Kruskal-Wallis test followed by Mann-Whitney $U$ test and presented as median (interquartile range). A value of $p<0.05$ was considered to be statistically significant.

\section{Results}

Table 1 shows the relative weight and epithelial height of male accessory reproductive organs of rats in all experimental groups. CS group had significantly increased weight of epididymis with increased epithelial height of its proximal part as well as increased weight of ventral prostate with decreased epithelial height compared to control and $\mathrm{H}$ groups. However, with the supplementation of honey in $\mathrm{H}+\mathrm{CS}$ group, the weight of ventral prostate as well as the epithelial height of epididymis and ventral prostate was significantly restored. Furthermore, no significant differences were observed for the relative weight of combined seminal vesicles and coagulating glands among all the groups.

Figure 1 shows the representative light microscopic feature of tubules in proximal cauda epididymis of rats from all the experimental groups. In CS group, the epithelial height and nuclear size were increased. However, in H+CS group, these changes were significantly restored. Figure 2 shows the representative light microscopic feature of tubules at the area between proximal and distal cauda epididymis of rats from all the experimental groups. Enlarged clear cell were observed in both CS and $\mathrm{H}+\mathrm{CS}$ groups. However, less number of enlarged clear cells was observed in $\mathrm{H}+\mathrm{CS}$ group as compared to CS group. Figure 3 shows the representative light microscopic feature of ventral prostate in rats from all the experimental groups. In CS group, there were marked interstitial oedema and decreased epithelial height of the tubules. However, these changes were minimal in $\mathrm{H}+\mathrm{CS}$ group. Furthermore, the accessory reproductive organs in rats from $\mathrm{H}$ group showed similar relative weight and structures with controls. Rats from all experimental groups showed normal seminal vesicles and coagulating gland with normal epithelial cells (data not shown). 
Publisher: African Networks on Ethnomedicines

Web page: /http://journals.sfu.ca/africanem/index.php/ajtcam/index

http://dx.doi.org/10.4314/ajtcam.v9i3.5

Table 1: Effects of honey and cigarette smoke on the relative weight and epithelial height of male accessory reproductive organs in rats.

\begin{tabular}{|c|c|c|c|c|c|}
\hline Parameters & Control & $\mathrm{H}$ & CS & $\mathrm{H}+\mathrm{CS}$ & $p$ \\
\hline Left epididymis (\%) ${ }^{@}$ & $0.14(0.01)$ & $0.14(0.01)$ & $0.17(0.03)^{\mathrm{a}, \mathrm{b}}$ & $0.17(0.02)^{\mathrm{a}, \mathrm{b}}$ & $<0.001^{£}$ \\
\hline Ventral prostate (\%) ${ }^{@}$ & $0.14(0.02)$ & $0.14(0.03)$ & $0.18(0.03)^{a, b}$ & $0.15(0.03)^{\mathrm{c}}$ & $<0.05^{£}$ \\
\hline Seminal vesicles with coagulating glands (\%) ${ }^{@}$ & $0.20(0.04)$ & $0.22(0.10)$ & $0.18(0.03)$ & $0.20(0.040)$ & $\mathrm{NS}^{£}$ \\
\hline Epithelial height of proximal cauda epididymis $(\mu \mathrm{m})^{\#}$ & $15.84(0.91)$ & $15.50(0.78)$ & $19.20(0.94)^{\mathrm{a}, \mathrm{b}}$ & $15.70(0.45)^{\mathrm{c}}$ & $<0.05^{\$}$ \\
\hline Epithelial height of ventral prostate $(\mu \mathrm{m})^{\#}$ & $14.03(0.95)$ & $14.83(0.87)$ & $8.20(0.92)^{\mathrm{a}, \mathrm{b}}$ & $11.49(0.50)^{\mathrm{a}, \mathrm{b}, \mathrm{c}}$ & $<0.05^{\$}$ \\
\hline
\end{tabular}

Values are ${ }^{\circledR}$ median (interquartile range) or ${ }^{\#}$ mean (SD). H, honey; CS, cigarette smoke; H+CS, honey plus CS; NS, not significant. ${ }^{£}$ Kruskal-Wallis test followed by MannWhitney $U$ test, ${ }^{\$}$ One-way analysis of variance followed by Tukey's HSD post-hoc test., ${ }^{a} p<0.05$ compared to control group, ${ }^{b} p<0.05$ compared to H group and ${ }^{c} p<0.05$ compared to CS group. 
Mohamed et al., Afr J Tradit Complement Altern Med. (2012) 9(3):329-335

Publisher: African Networks on Ethnomedicines

Web page: /http://journals.sfu.ca/africanem/index.php/ajtcam/index

http://dx.doi.org/10.4314/ajtcam.v9i3.5
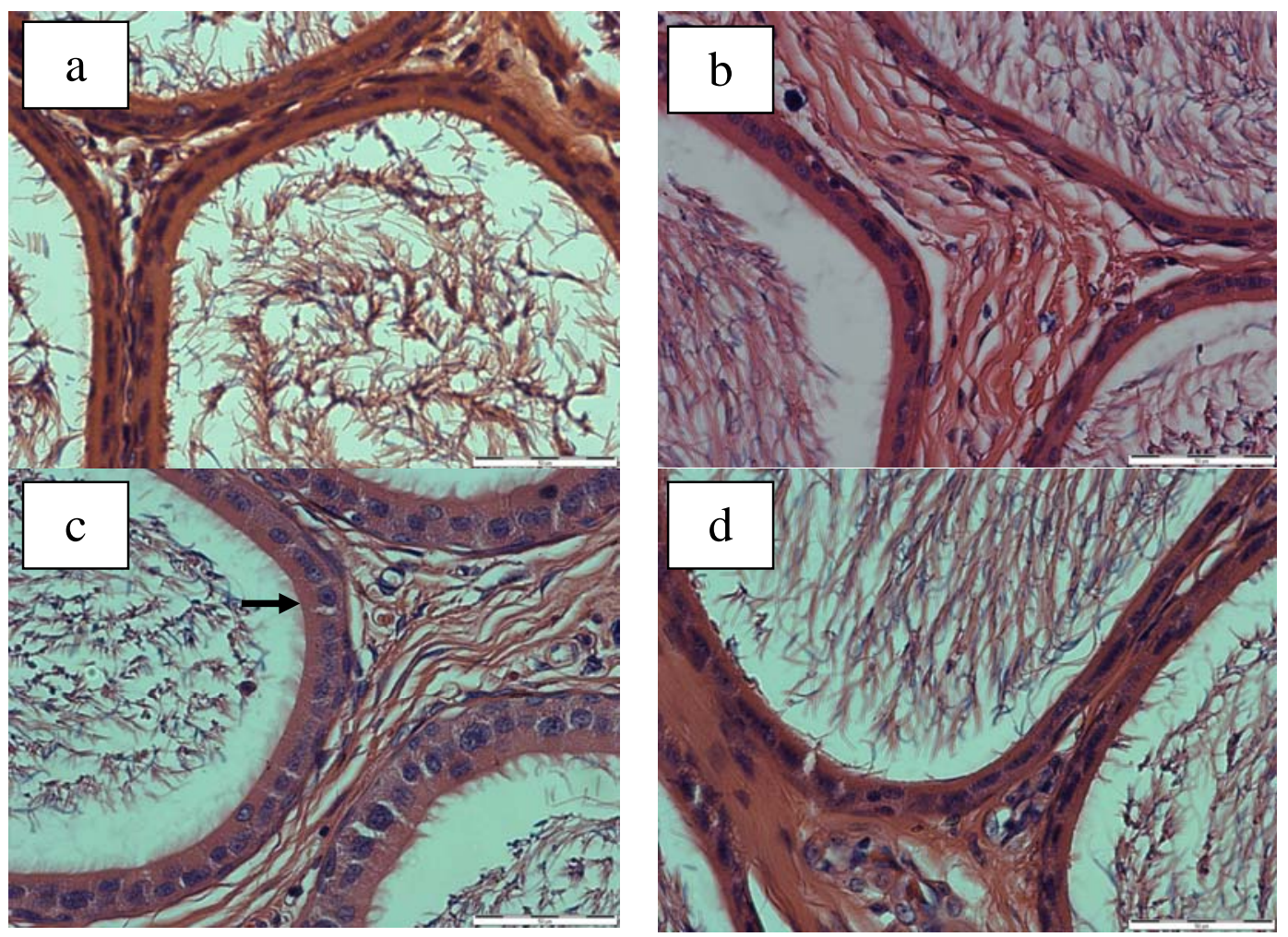

Figure 1: Representative light microscopic feature of tubules in proximal cauda epididymis of rats. The tubules from control (a) and $\mathrm{H}$ (b) groups showed tubules with normal epithelial height and nuclear size. In CS group (c), the epithelial height and nuclear size were enlarged (arrow). However in $\mathrm{H}+\mathrm{CS}$ group (d), the epithelial height and nuclear size were smaller than CS group and similar with control and $\mathrm{H}$ groups. $\mathrm{H}$, honey; CS, cigarette smoke; $\mathrm{H}+\mathrm{CS}$, honey plus CS. (H \& E staining, bar $=50 \mu \mathrm{m}$, magnification 100x).

\section{Discussion}

This study was undertaken to investigate the effect of CS on histology of male accessory reproductive organs in rats and the possible protective effect of honey supplementation. CS significantly increased relative weight of ventral prostate and epididymis. However, another study shows decreased relative weight of epididymis and vas deference following treatment of nicotine intraperitoneally for 30 days (Londonkar et al., 1997). This discrepancy could be explained, at least in part, by the difference in the toxic agent used and duration of treatment whereby the rats were exposed to CS for 13 weeks in the present study. Nevertheless, the changes in male reproductive organs weight (either increase or decrease) are significant findings that could be due to the changes in the structure, function or both of the organs (Creasy, 2001). Therefore, the significant changes in the relative weight of ventral prostate and epididymis in the present study might suggest the toxic effect of CS on the structure, function or both of these organs. Interestingly, with the supplementation of honey, the relative weight of prostate was restored suggesting the protective effect of honey against the toxic effect of CS on the weight of rat prostate.

CS significantly caused increases in height and nuclear size of the epithelial cells especially principal cells in the proximal cauda epididymis along with increases in size and number of clear cells in the region between proximal and distal caudal epididymis. These histological changes have also been observed when the rats were treated with other toxic substances such as cyclophosphamide and gossypol suggesting the presence of increased phagocytosis within these epithelial cells (Trasler et al., 1988, de Andrade et al., 2006). This is further supported by an experimental study showing that clear cells have an active role in phagocytosing the cytoplasmic droplets originating from sperm (Hermo et al., 1988). In addition, some of the abnormal sperms are found to be phagocytosed by the epididymal epithelial cells (Sutovsky et al., 2001, Aruldhas et al., 2006). Therefore, it is plausible to suggest that the findings on the improved histological changes in the epididymis of rats from $\mathrm{H}+\mathrm{CS}$ group could possibly be contributed by the reduced phagocytosis within the principal and clear cells. 
Mohamed et al., Afr J Tradit Complement Altern Med. (2012) 9(3):329-335

Publisher: African Networks on Ethnomedicines

Web page: /http://journals.sfu.ca/africanem/index.php/ajtcam/index

http://dx.doi.org/10.4314/ajtcam.v9i3.5
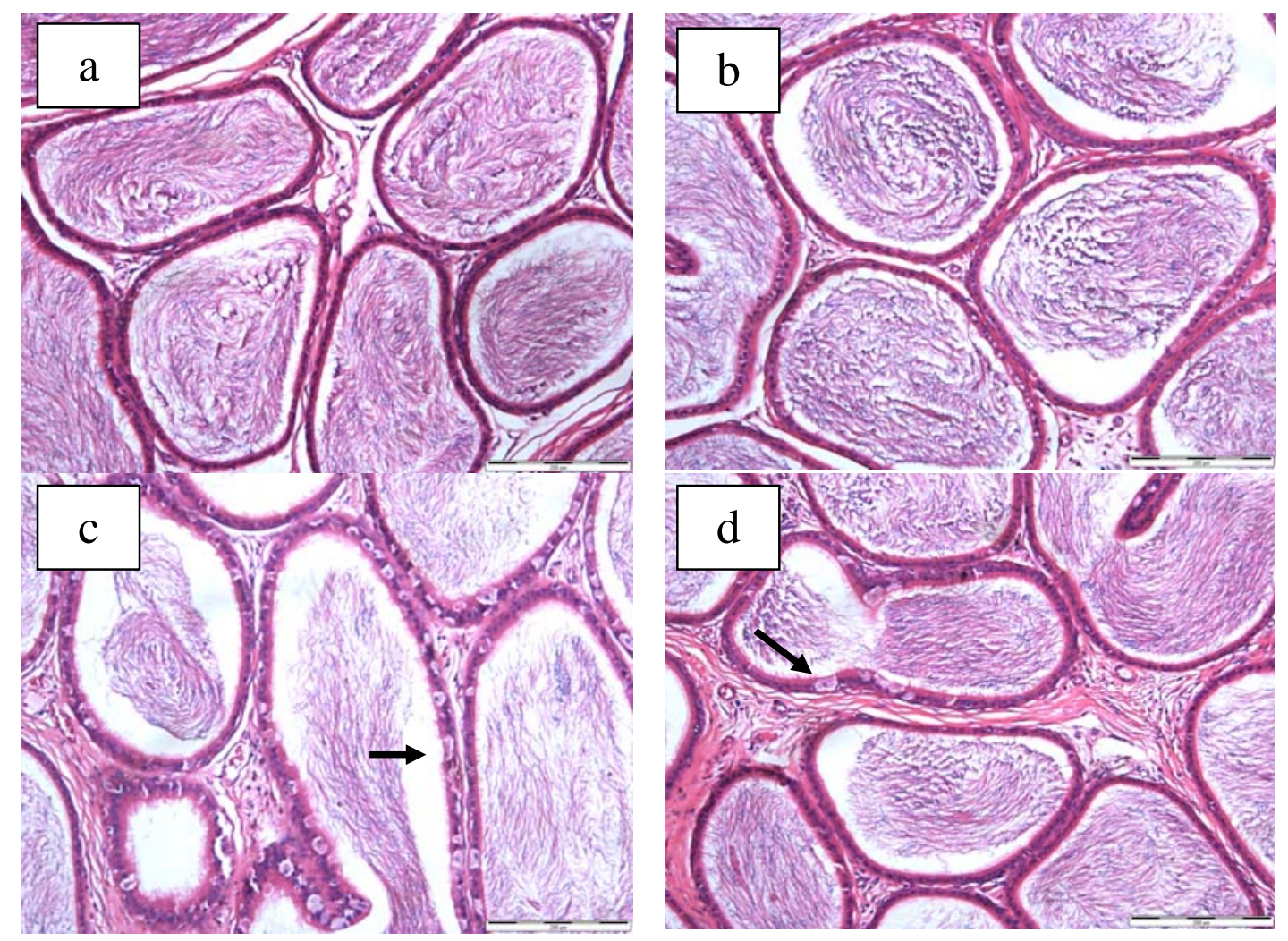

Figure 2: Representative light microscopic feature of tubules at the area between proximal and distal cauda epididymis of rats. Normal size of clear cells was observed in control (a) and $\mathrm{H}$ (b) groups while enlarged clear cells (arrow) were observed in CS (c) and $\mathrm{H}+\mathrm{CS}$ (d) groups. However, less number of enlarged clear cells was observed in rats from $\mathrm{H}+\mathrm{CS}$ group as compared with CS group. $\mathrm{H}$, honey; CS, cigarette smoke; $\mathrm{H}+\mathrm{CS}$, honey plus CS. $(\mathrm{H} \& \mathrm{E}$ staining, bar = $200 \mu \mathrm{m}$, magnification 100x).

Ventral prostate with significantly decreased epithelial height and marked interstitial oedema were observed in rats from CS group. These findings are similar with other study which shows atrophy of the epithelial cells of the prostate in rats treated with nicotine for 90 days (Carvalho et al., 2006). The histological findings, partly, might contribute to the changes in relative weight of ventral prostate in rats when exposed to CS. However, these histological changes were significantly reduced with the supplementation of honey suggesting the protective effect of honey against the toxic effect of CS on the structures of rat prostate. Oxidative damage has been postulated as one of the mechanisms that caused testicular toxicity following exposure to CS (Rajpurkar et al., 2000a). Honey has been reported to have antioxidants such as vitamins A and E (Al-Waili, 2003), catalase (Gheldof et al., 2002), flavanoids (Yao et al., 2004) and possesses antiradical and antioxidant properties (Mohamed et al., 2010). Therefore, it is plausible to suggest that the effect of honey in attenuating the CS-induced toxicity to the epididymis and ventral prostate of male rats in this study could be partly mediated by its counteraction on oxidative stress within these organs via its antioxidant property. Thus, further study is suggested to determine the levels of oxidative stress markers in these organs to support this postulate.

In conclusion, CS significantly increased relative weight and changes on the histology of epididymis and ventral prostate in rats. Supplementation of honey significantly reduced these changes except for the weight of epididymis. This study might suggest that honey has protective effect against CS-induced toxicity on epididymis and ventral prostate in rats. Further studies are needed to elucidate its exact mechanism of action and the possible beneficial role of honey supplementation in protecting against or treating the accessory reproductive organs problems related to oxidative damage in humans. 

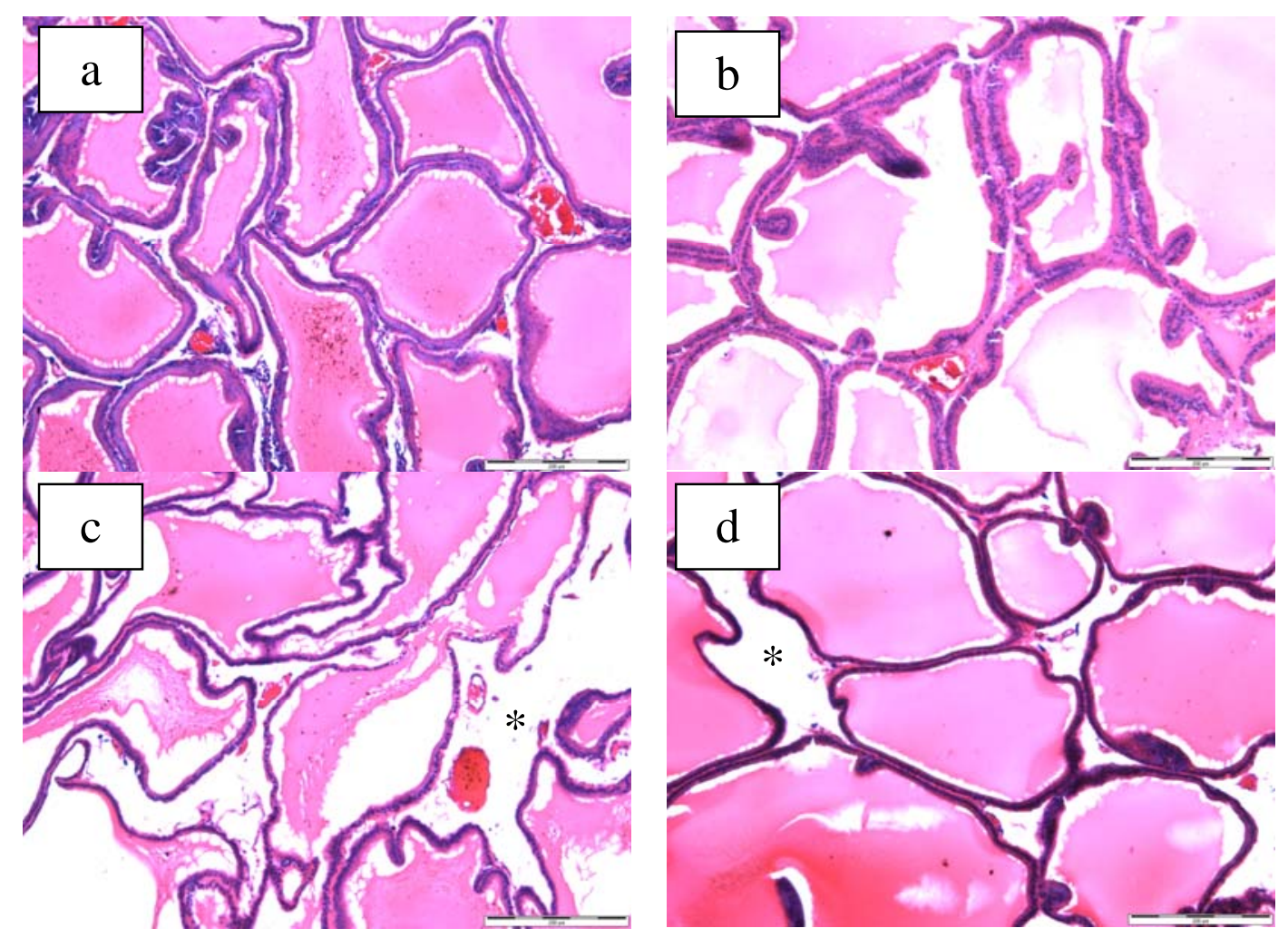

Figure 3: Representative light microscopic feature of rat ventral prostate. Ventral prostate from control (a) and H (b) groups showed tubules with normal epithelial height. In CS group (c), there were marked interstitial oedema $(*)$ and decreased epithelial height. However, these changes were minimal in $\mathrm{H}+\mathrm{CS}$ group (d). H, honey; CS, cigarette smoke; $\mathrm{H}+\mathrm{CS}$, honey plus CS. (H \& E staining, bar $=200 \mu \mathrm{m}$, magnification 100x).

\section{Acknowledgements}

We are grateful to Universiti Sains Malaysia for funding this study (304/PPSP/6131586) and Federal Agricultural Marketing Authority, Malaysia for supplying the honey.

\section{References}

1. Ahmadnia, H., Ghanbari, M., Moradi, M. R. and Khaje-Dalouee, M. (2007). Effect of cigarette smoke on spermatogenesis in rats. Urol. J., 4: 159-163.

2. Al-Waili, N. S. (2003). Effects of daily consumption of honey solution on hematological indices and blood levels of minerals and enzymes in normal individuals. J. Med. Food, 6: 135-140.

3. Aruldhas, M. M., Subramanian, S., Sekhar, P., Vengatesh, G., Govindarajulu, P. and Akbarsha, M. A. (2006). In vivo spermatotoxic effect of chromium as reflected in the epididymal epithelial principal cells, basal cells, and intraepithelial macrophages of a nonhuman primate (Macaca radiata Geoffroy). Fertil. Steril., 86: 1097-1105.

4. Beretta, G., Granata, P., Ferrero, M., Orioli, M. and Facino, R. M. (2005). Standardization of antioxidant properties of honey by combination of spectrophotometric/fluorometric assays and chemometrics. Anal. Chim. Acta, 533: 185-191.

5. Carvalho, C. A., Favaro, W. J., Padovani, C. R. and Cagnon, V. H. (2006). Morphometric and ultrastructure features of the ventral prostate of rats (Rattus norvegicus) submitted to long-term nicotine treatment. Andrologia, 38: 142-151.

6. Cesar-Neto, J. B., Duarte, P. M., Sallum, E. A., Barbieri, D., Moreno, H., Jr. and Nociti, F. H., Jr. (2003). A comparative study on the effect of nicotine administration and cigarette smoke inhalation on bone healing around titanium implants. J. Periodontol., 74: 1454-1459. 
Publisher: African Networks on Ethnomedicines

Web page: /http://journals.sfu.ca/africanem/index.php/ajtcam/index

http://dx.doi.org/10.4314/ajtcam.v9i3.5

7. Creasy, D. M. (2001). Pathogenesis of male reproductive toxicity. Toxicol. Pathol., 29: 64-76.

8. de Andrade, S. F., Oliva, S. U., Klinefelter, G. R. and De Grava Kempinas, W. (2006). Epididymis-specific pathologic disorders in rats exposed to gossypol from weaning through puberty. Toxicol. Pathol., 34: 730-737.

9. Gheldof, N., Wang, X. H. and Engeseth, N. J. (2002). Identification and quantification of antioxidant components of honeys from various floral sources. J. Agric. Food Chem., 50: 5870-5877.

10. Hermo, L., Dworkin, J. and Oko, R. (1988). Role of epithelial clear cells of the rat epididymis in the disposal of the contents of cytoplasmic droplets detached from spermatozoa. Am. J. Anat., 183: 107-124.

11. Londonkar, R. L., Srinivasreddy, P., Somanathreddy, P. and Patil, S. B. (1997). Nicotine induced inhibition of the activities of accessory reproductive ducts in male rats. J. Ethnopharmacology, 60: 215-221.

12. Mohamed, M., Sirajudeen, K. N. S., Swamy, M., Yaacob, N. S. and Sulaiman, S. A. (2010). Studies on the antioxidant properties of tualang honey of Malaysia. Afr. J. Trad. CAM., 7: 59-63.

13. Perez, E., Rodriguez-Malaver, A. J. and Vit, P. (2006). Antioxidant capacity of Venezuelan honey in wistar rat homogenates. J. Med. Food, 9: 510-516.

14. Rajpurkar, A., Dhabuwala, C. B., Jiang, Y. and Li, H. (2000b). Chronic cigarette smoking induces an oxidantantioxidant imbalance in the testis. J. Environ. Pathol. Toxicol. Oncol., 19: 369-373.

15. Rajpurkar, A., Li, H. and Dhabuwala, C. B. (2000a). Morphometric analysis of rat testis following chronic exposure to cigarette smoke. J. Environ. Pathol. Toxicol. Oncol., 19: 363-368.

16. Sutovsky, P., Moreno, R., Ramalho-Santos, J., Dominko, T., Thompson, W. E. and Schatten, G. (2001). A putative, ubiquitin-dependent mechanism for the recognition and elimination of defective spermatozoa in the mammalian epididymis. J. Cell. Sci., 114: 1665-1675.

17. Trasler, J. M., Hermo, L. and Robaire, B. (1988). Morphological changes in the testis and epididymis of rats treated with cyclophosphamide: a quantitative approach. Biol. Reprod., 38: 463-479.

18. Yao, L., Jiang, Y., D'Arcy, B., Singanusong, R., Datta, N., Caffin, N. and Raymont, K. (2004). Quantitative highperformance liquid chromatography analyses of flavonoids in Australian Eucalyptus honeys. J. Agric. Food Chem., 52: 210214.

19. Yardimci, S., Atan, A., Delibasi, T., Sunguroglu, K. and Guven, M. C. (1997). Long-term effects of cigarette-smoke exposure on plasma testosterone, luteinizing hormone and follicle-stimulating hormone levels in male rats. Br. J. Urol., 79: 66-69. 